\title{
Primeiro relato de Stiretrus decastigmus no Brasil predando Microtheca ochroloma
}

\author{
First report of Stiretrus decastigmus in Brazil preying Microtheca ochroloma
}

\author{
Sônia Poncio' ${ }^{\text {Sônia Thereza Bastos Dequech }}{ }^{\text {II }}$ Vinícius Soares Sturza ${ }^{\text {III }}$ \\ Rael Alfredo Duarte Lissner ${ }^{\mathrm{III}}$ Luis Fernando Perlin ${ }^{\mathrm{III}}$ Pedro Krauspenhar Rosalino ${ }^{\mathrm{III}}$ \\ Leandro do Prado Ribeiro ${ }^{\mathrm{IV}}$
}

\begin{abstract}
Em razão da importância de Microtheca ochroloma (Coleoptera: Chrysomelidae) como inseto-praga de Brassicaceae e da carência de informações relativas aos inimigos naturais desse crisomelídeo, o presente trabalho visa a relatar, pela primeira vez, a ocorrência de Stiretrus decastigmus (Hemiptera: Pentatomidae) predando $\boldsymbol{M}$. ochroloma em cultivo de Brassica chinensis L., em Santa Maria, Rio Grande do Sul, Brasil (latitude: 2943'28”, S, longitude: 5343'19”O e altitude: 95m). Também são descritas a metodologia de coleta e as características morfológicas dos espécimes encontrados.
\end{abstract}

Palavras-chave: Pentatomidae, predadores, Chrysomelidae.

\section{ABSTRACT}

Due to the importance of Microtheca ochroloma (Coleoptera: Chrysomelidae) as an insect-pest of Brassicaceae and to the lack of data regarding its natural enemies, the present research aims to report the first occurrence of Stiretrus decastigmus (Hemiptera: Pentatomidae) preying M. ochroloma in Brassica chinensis L., at Santa Maria, Rio Grande do Sul state, Brazil (latitude: 2943'28”S, longitude: 5343'19”O, height: 95m). The collecting methodology and morphologic characteristics of the insects found were also described.

Key words: Pentatomidae, predators, Chrysomelidae.
O crisomelídeo Microtheca ochroloma Stal é um inseto-praga de Brassicaceae que causa desfolhamento nas plantas durante as fases larval e adulta (FASULO, 2005). As perdas econômicas ocasionadas por esse inseto podem inviabilizar a produção e a comercialização de cultivos, como o de couve-chinesa (Brassica chinensis L.) (DEQUECH et al., 2008).

O controle de $\boldsymbol{M}$. ochroloma é realizado por meio de produtos químicos, visto que outros métodos de controle não vêm demonstrando uma eficácia satisfatória a campo, o que limita a implementação de um manejo integrado (BOWERS, 2003). Demonstra-se, assim, a carência de alternativas de controle que possam ser estudadas, visando a uma produção satisfatória e segura para os consumidores.

Portanto, em razão da importância de $\boldsymbol{M}$. ochroloma em brassicáceas, em especial em cultivos realizados por produtores orgânicos na região de Santa Maria, Rio Grande do Sul (RS), estudos vêm sendo realizados com esse inseto pelo Setor de Entomologia do Departamento de Defesa Fitossanitária (DFS), Centro de Ciências Rurais (CCR), Universidade Federal de Santa Maria (UFSM).

\footnotetext{
IPrograma de Pós-graduação em Agronomia, Universidade Federal de Santa Maria (UFSM), 97105-900, Santa Maria, RS, Brasil. Email: soniaponcio@yahoo.com.br. Autor para correspondência.

IDDepartamento de Defesa Fitossanitária, UFSM, Santa Maria, RS, Brasil.

IIICurso de Agronomia, UFSM, Santa Maria, RS, Brasil.

${ }^{\text {IV} P r o g r a m a ~ d e ~ P o ́ s-g r a d u a c ̧ a ̃ o ~ e m ~ E n t o m o l o g i a, ~ E s c o l a ~ S u p e r i o r ~ d e ~ A g r i c u l t u r a ~ “ L u i z ~ d e ~ Q u e i r o z ” ~(E S A L Q), ~ P i r a c i c a b a, ~ S P, ~ B r a s i l . ~}$
} 
No dia 10 de novembro de 2008, em área experimental do Departamento de Fitotecnia, CCR/ UFSM, com cultivos de couve-chinesa (latitude: 2943'28’'S, longitude: 5343’19’O e altitude: $95 \mathrm{~m}$ ), foram encontrados três exemplares de percevejo alimentando-se de adultos e de larvas de $\boldsymbol{M}$. ochroloma. Os exemplares foram coletados, mortos por congelamento e, posteriormente, enviados para o Museu de Ciências Naturais da Fundação Zoobotânica do Rio Grande do Sul, para a identificação da espécie.

Os exemplares foram identificados como sendo pertencentes à espécie Stiretrus decastigmus (Herrich-Schaeffer, 1838), subfamília Asopinae, família Pentatomidae, (Hemiptera, Heteroptera), e estão depositados sob os números 180.502, 180.503 e 180.504 na coleção do Museu de Ciências Naturais da Fundação Zoobotânica do Rio Grande do Sul (MCNZ) - (voucher specimens).

Na literatura consultada, foi encontrado apenas um único registro de distribuição desse pentatomídeo, abrangendo a Argentina, o Brasil, a Bolívia e o Paraguai (THOMAS, 1992). Este é o primeiro relato da ocorrência de $\boldsymbol{S}$. decastigmus predando $\boldsymbol{M}$. ochroloma, além de não ter sido encontrada referência de outros organismos sendo predados por $\boldsymbol{S}$. decastigmus no Brasil.

Pentatomídeos pertencentes à espécie $\boldsymbol{S}$. decastigmus são polimórficos, podendo haver indivíduos de forma negra com manchas vermelhas ou amarelas, verde-metálica, acobreada ou, ainda, azul (THOMAS, 1992). Entre os insetos coletados, um apresentava forma negra com manchas vermelhas (Figuras 1a e 1b), e os outros dois apresentavam coloração acobreada (Figuras 1c e 1d).

Espécimes da subfamília Asopinae caracterizam-se por apresentar hábitos predatórios e são reconhecidos como agentes potenciais de controle biológico (GRAZIA et al., 1999). No Brasil, essa subfamília possui registros dos gêneros Supputius e Podisus como sendo predadores de pragas de culturas agrícolas e florestais (SILVA et al., 1997; PIRES et al., 2006). Quanto ao gênero Stiretrus, há registros de $\boldsymbol{S}$. anchorago nos EUA como sendo inimigo natural de larvas de lepidópteros e coleópteros em cultivos de soja, de milho e de alfafa (RICHMAN \& MEAD, 2008).

Após o registro da ocorrência de $\boldsymbol{S}$. decastigmus predando $\boldsymbol{M}$. ochroloma, devem ser realizados estudos visando a avaliar a utilização desse

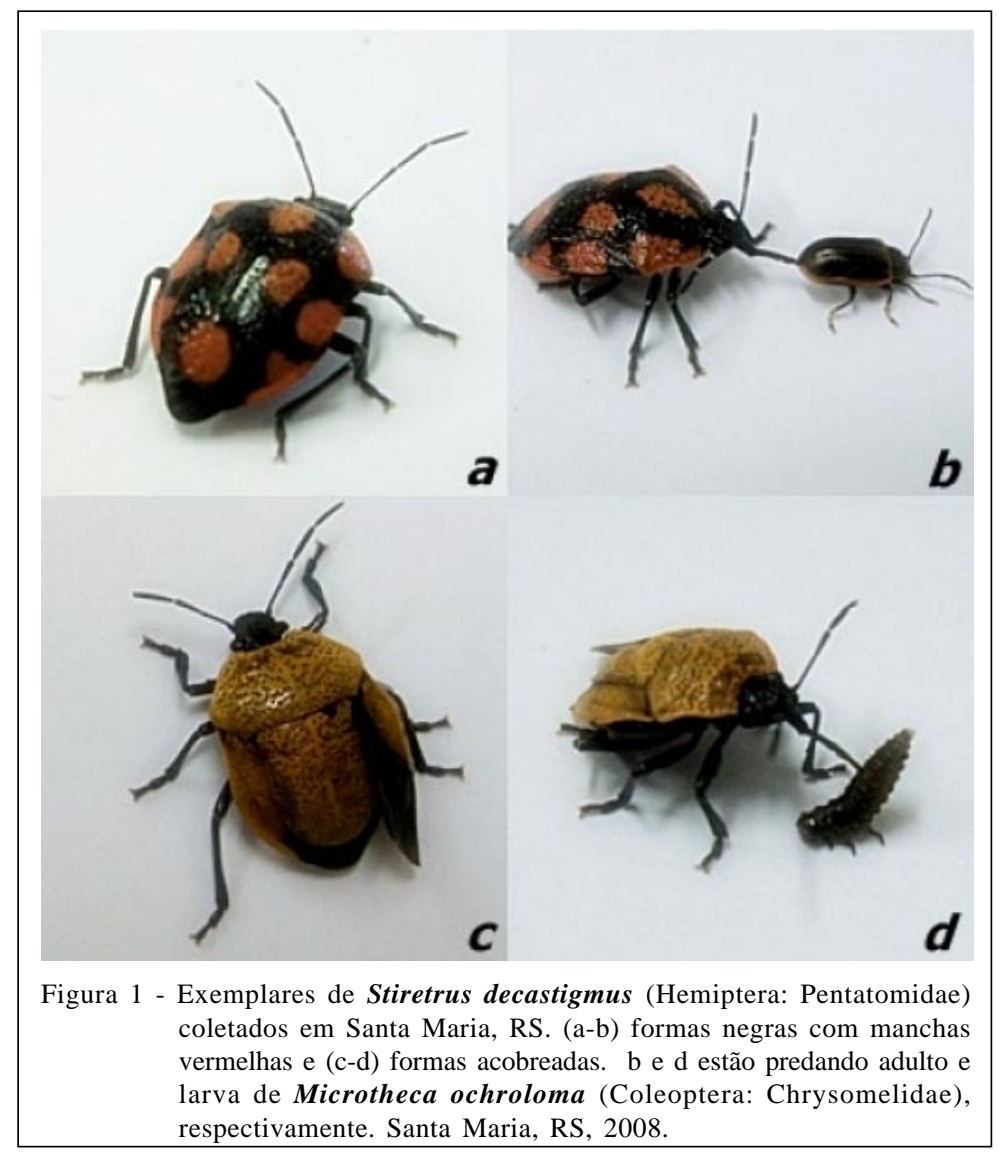

Ciência Rural, v.40, n.5, mai, 2010. 
predador como agente de controle biológico de $\boldsymbol{M}$. ochroloma em agroecossistemas com cultivos de brassicáceas.

\section{AGRADECIMENTOS}

À Doutora Aline Barcelos, do Museu de Ciências Naturais da Fundação Zoobotânica do Rio Grande do Sul, pela identificação da espécie e disponibilização de material bibliográfico.

\section{REFERÊNCIAS}

BOWERS, K. Effects of within-field location of host plants and intercropping on the distribution of Microtheca ochroloma (Stal) in Mizuna. 2003. 63f. Tese. University of Florida, Gainesville, Florida, United States of America. Disponíve em: <http://etd.fcla.edu/UF/UFE0000650/bowers_k.pdf>. Acesso em: 20 mar. 2009.

DEQUECH, S.T.B. et al. Efeito de extratos de plantas com atividade inseticida no controle de Microtheca ochroloma Stal (Col.: Chrysomelidae), em laboratório. Revista Biotemas v.21, n.1, p.41-46, 2008. Disponível em: <http:// www.biotemas.ufsc.br/volumes/pdf/volume211/p41a46.pdf> Acesso em: 23 mar. 2009.

FASULO, T.R. Yellowmargined leaf beetle, Microtheca ochroloma (Stal) (Insecta: Coleoptera: Crhysomelidae). Gainesville: University of Florida, IFAS Extension, 2005. 5p. Acessado em: 30 mar. 2009. Disponível em: <http://
edis.ifas.ufl.edu/pdffiles/IN/IN62500.pdf>. Acesso em: 30 mar. 2009.

GRAZIA, J. et al. Pentatomoidea. In: BRANDÃO, C.R.F.; CANCELLO E.M. (Org.) Biodiversidade do Estado de São Paulo, Brasil: síntese do conhecimento ao final do século XX, 5: invertebrados terrestres. São Paulo: FAPESP, 1999. p.101-112.

PIRES, E.M. et al. Potencial reprodutivo horário do predador de lagartas desfolhadoras do eucalipto: Podisus nigrispinus (Heteroptera: Pentatomidae). Revista Árvore, Viçosa, v.30, n.6, p.1039-1044. 2006. Disponível em: <http:/ /www.scielo.br/pdf/rarv/v30n6/a20v30n6.pdf>. Acesso em: 30 mar. 2009. doi: 10.1590/S0100-67622006000600020.

RICHMAN, D.B.; MEAD, F.W. Predatory stinck bug, Stiretrus anchorago (Fabricius) (Insecta: Hemiptera: Pentatomidae). Gainesville: University of Florida, IFAS Extension, 2008. 4p. Disponível em: <http://edis.ifas.ufl.edu/ pdffiles/IN/IN38600.pdf>. Acesso em: 30 mar. 2009.

SILVA, E.N. et al. Consumo alimentar e crescimento do predador Supputius cincticeps (Stäl) (Heteroptera: Pentatomidae) alimentando-se de lagartas do curuquerê-do-algodoeiro. Anais da Sociedade Entomológica do Brasil, v.26, n.2, p.349357, 1997.

THOMAS, D.B. Taxonomic synopsis of the Asopine Pentatomoidae (Heteroptera) of the Western Hemisphere. The Thomas Say Foundation. Lanham: Entomological Society of America, 1992. V.16, 147p. 